\title{
Assessment of welfare issues during traditional slaughter of goats in Pretoria,
}

\section{South Africa}

\author{
Daniel N. Qekwana ${ }^{1} *$, Cheryl M.E. McCrindle ${ }^{2}$, James W. Oguttu ${ }^{3}$, Delia Grace ${ }^{4}$, Beniamino T. \\ Cenci-Goga ${ }^{1,5}$
}

\author{
${ }^{1}$ Faculty of Veterinary Science, Section Veterinary Public Health, Department of Paraclinical Science, University of \\ Pretoria, Private Bag X04, 0110 Onderstepoort, South Africa, \\ ${ }^{2}$ School of Health Systems and Public Health, Faculty of Health Sciences, University of Pretoria, Pretoria 0001, South \\ Africa \\ ${ }^{3}$ Department of Agriculture and Animal Health, College of Agriculture and Environmental Science, University of South \\ Africa, Private Bag X11, 1710 Florida, South Africa, \\ ${ }^{4}$ ILRI-Kenya, P.O. Box 30709, Nairobi, Kenya, 00100, \\ ${ }^{5}$ Università degli Studi di Perugia, Dipartimento di Medicina Veterinaria, Via San Costanzo, 06121 Perugia, Italy
}

*Faculty of Veterinary Science, Section Veterinary Public Health, Department of Paraclinical Science, University of Pretoria, Private Bag X04, 0110 Onderstepoort, South Africa, nenene.qekwana@up.ac.za

Keywords: traditional slaughter, animal welfare, welfare assessment, South Africa

\section{Acknowledgments}

Funding from the International Livestock Research Institute-Safe Food Fair Food Project and the National Research Foundation is gratefully acknowledged. This study was approved by the Ethics Committee of the Faculty of Veterinary Science at the University of Pretoria.

\begin{abstract}
Goats are traditionally slaughtered to celebrate marriages and births; venerate the ancestors; address personal problems or during funerals. The objective of this study was to assess animal welfare issues associated with the traditional slaughter of goats in and around Pretoria, South Africa. Participatory research methods were used to interview 105 respondents. Four of those interviewed were visited to observe the slaughter process. The most common method of transport was a vehicle (47\%), followed by on foot $(30 \%)$. The distance travelled $(68 \%)$ was usually $<10 \mathrm{~km}$, and in all cases $<50 \mathrm{~km}$. The most common (57\%) method of restraining goats during transport was by tying all four legs together. While, during slaughter the head and legs of the goat were held by assistants (55\%). Prior to slaughter, the majority of goats were tied under a tree $(66 \%)$. In total, $97 \%$ of the goats were slaughtered within 24 hours and no stunning was performed. In this study, animal welfare problems were widespread and research should be undertaken to find practical ways of addressing animal welfare issues during traditional slaughter.
\end{abstract}




\section{Introduction}

In recent years, the interest in animal welfare issues has increased globally. In particular, there are strong opinions, both favourable and unfavourable, about livestock welfare during traditional and cultural slaughter (Brown, 2014; Jacques, 2014; Salamano et al., 2013; Wyatt, 2015). This is also the case in South Africa (Behrens, 2009).

Previous studies have tried to define animal welfare and develop measurable welfare indicators for different livestock species (Ohl \& van der Staay, 2012; Sneddon, Elwood, Adamo, \& Leach, 2014). However, much of this research has focused on livestock welfare in intensive systems or conventional settings such as registered abattoirs. Authors may have avoided assessment of welfare during traditional slaughter for political or social reasons. The result is that there is limited information on livestock welfare indicators during traditional slaughter not only in Africa but globally. It is surprising because in the EU and USA where religious rights are also protected by legislation, slaughter of livestock for traditional purposes is permitted by law under specified conditions (Council of the European Union, 2009; Shaddow, 1991). Therefore, as has been done for abattoirs in developed countries, welfare indicators for traditional slaughter, should have been developed. Globally, the lack of pre-slaughter stunning during religious slaughter at abattoirs has been the most controversial area (Grandin, 2014).

Livestock welfare is more easily assessed during conventional slaughter. In contrast, welfare issues that occur during traditional slaughter are often complex and multifactorial. Political, cultural and economic concerns seem to be the main drivers for welfare of livestock, slaughtered for traditional purposes (Masiga \& Munyua, 2005; Molomo \& Mumba, 2014). Therefore, the interpretations and perspectives of animal welfare issues may differ depending on the religion and type of practices. Recent studies have also demonstrated that perceptions of animal welfare also differ depending on whether the person asked is a farmer, an urban dweller or a vegetarian (Tuyttens, Vanhonacker, Van Poucke, \& Verbeke, 2010; Vanhonacker, Verbeke, Van Poucke, \& Tuyttens, 
2008). Therefore, when defining animal welfare issues, intangibles such as moral values of consumers should also be considered (Ohl \& van der Staay, 2012).

Although welfare indicators for livestock raised for slaughter in registered abattoirs have been well described, publications on informal slaughter for traditional, customary, ritual or religious purposes are lacking (Grandin, 1991; Grandin, 1998; Gregory, 2008; Velarde \& Dalmau, 2012). This study consequently aims to describe animal welfare issues that arise during slaughter of goats for traditional or ritual purposes in Pretoria, South Africa.

\section{Materials and Methods}

Interviewers were stationed at four taxi ranks and 18 informal markets in and around Pretoria. A "taxi rank" in South Africa refers to a place where taxis park while awaiting commuters. A total of 300 people who passed by at these locations were asked if they had been involved in ritual slaughter and if they were willing to be interviewed. Therefore, the criteria for inclusion in the study were: the respondents had to agree to interviewed and must have been involved in traditional slaughter of goats as a spectator or participant. In total 105 of those respondents approached, were interviewed using structured questionnaires and informed consent was obtained from each participant. Well-trained animal health students conducted the interviews in the home language of respondents (Qekwana, D., McCrindle, C., Oguttu,J., 2014; N. D. Qekwana \& Oguttu, 2014).

The questionnaire was designed and analysed using Excel (Microsoft, Redmond, WA, USA) and SAS statistical software, Version 9.4 (SAS Institute Inc., Cary, North Carolina, USA). Three categories of variables were included in the questionnaire: animal welfare conditions during transportation; at the holding area; and, during slaughter. Respondents were asked a total of 12 questions related to animal welfare of goats. Furthermore, visits were made to four traditional slaughter ceremonies to evaluate the practices.

Data was evaluated for missing values and any inconsistencies. Open-ended questions were analysed using the word-based technique described by Ryan and Bernard (Ryan \& Bernard, 2003). 
Descriptive statistical analysis using frequency tables and proportions were used to display and compare observational data.

\section{Results}

\section{$\underline{\text { Demographic profile }}$}

Of the 105 respondents interviewed, 54\% (CI: 44-64) were men and 46\% (CI: 36-56) women. The majority (62\%, CI: 52-71) came from Gauteng Province and the rest (38\%, CI: 29-48) from other provinces.

\section{$\underline{\text { Animal welfare conditions during transport }}$}

As can be seen in Table 1, the highest proportion (47\%) of respondents said motor cars were used to transport live goats, while (30\%) said the goat was moved on foot. The rest said either a trailer, bus, truck or taxi was used. Sixty percent (60\%) of the respondents who mentioned vehicles

\begin{tabular}{|c|c|c|c|c|}
\hline \multirow[b]{2}{*}{ Questions } & \multirow[b]{2}{*}{ Answers } & \multicolumn{3}{|c|}{ Respondents } \\
\hline & & n & $\%$ & CI: $95 \%$ \\
\hline \multirow[t]{6}{*}{ Method of transport used } & Car & 49 & 47 & $37-57$ \\
\hline & Foot & 31 & 30 & $21-39$ \\
\hline & Trailer & 8 & 8 & $3-14$ \\
\hline & Bus & 8 & 8 & $3-14$ \\
\hline & Truck & 6 & 6 & $2-12$ \\
\hline & Taxi & 3 & 3 & $1-8$ \\
\hline \multirow[t]{2}{*}{ Does the vehicle have a protective cover } & Yes & 19 & 40 & $26-55$ \\
\hline & No & 29 & 60 & $45-74$ \\
\hline \multirow[t]{5}{*}{ Method of restraint used during transport. } & Tied legs & 60 & 57 & $47-67$ \\
\hline & No restrain & 20 & 19 & $12-28$ \\
\hline & Tied head & 19 & 18 & $11-27$ \\
\hline & Held the animal & 5 & 5 & $2-11$ \\
\hline & Sack & 1 & 1 & $0-5$ \\
\hline \multirow{5}{*}{ Distance travelled from source to slaughter } & $0-10 \mathrm{~km}$ & 48 & 68 & $55-78$ \\
\hline & $11-20 \mathrm{~km}$ & 11 & 15 & $8-26$ \\
\hline & $21-30 \mathrm{~km}$ & 8 & 11 & $5-21$ \\
\hline & $31-40 \mathrm{~km}$ & 2 & 3 & $0-10$ \\
\hline & $41-50 \mathrm{~km}$ & 2 & 3 & $0-10$ \\
\hline \multirow[t]{2}{*}{ Are feed and water given during transport } & Yes & 17 & 19 & $12-29$ \\
\hline & No & 71 & 81 & $71-88$ \\
\hline
\end{tabular}


as a method of transport indicated that they did not use protective covers. The most common method of restraint during transport (57\%) was tying the legs together. The majority of respondents $(68 \%)$ said that goats were transported within a 10 kilometre radius of the slaughter location. Only $19 \%$ of respondents indicated that feed and water were provided during transport (Table 1).

\section{Animal welfare issues at the holding area}

The majority of respondents $(66 \%)$ indicated that the goat was tied to a tree just before slaughter, while $29 \%$ indicated that they were put into a kraal (pen). A few respondents (3\%) indicated that the goats were slaughtered as soon as they arrived (Table 2). Based on the answers from 75 respondents, most $(72 \%)$ kept the animal for 12 hours before slaughter and $25 \%$ kept them for 13 to 24 hours. Very few (3\%) said that goats were kept for more than 30 hours before slaughter. Over half $(53 \%)$ said that there was no shelter available for a goat prior to slaughter. Feed and water was provided in only $65 \%$ of cases.

\section{TABLE 2: KEEPING CONDITIONS, HOURS ANIMALS KEPT, SHELTER PROVIDED, FEED AND WATER} AT THE HOLDING AREA.

\begin{tabular}{|c|c|c|c|c|}
\hline \multirow[b]{2}{*}{ Questions } & \multirow[b]{2}{*}{ Answers } & \multicolumn{3}{|c|}{ Respondents } \\
\hline & & $\mathbf{n}$ & $\%$ & $\begin{array}{l}\text { CI: } \\
95 \%\end{array}$ \\
\hline \multirow[t]{5}{*}{ Where is the animal kept? } & Tied under a tree & 59 & 66 & $55-76$ \\
\hline & Kraal & 26 & 29 & $20-40$ \\
\hline & Slaughter immediately & 3 & 3 & $1-10$ \\
\hline & Cage & 1 & 1 & $0-6$ \\
\hline & House & 0 & 0 & $0-4$ \\
\hline \multirow[t]{5}{*}{ For how long is it kept before slaughter } & $<8 \mathrm{hr}$ & 28 & 37 & $26-49$ \\
\hline & $9-12 \mathrm{hr}$ & 26 & 35 & $24-47$ \\
\hline & $13-24 \mathrm{hr}$ & 19 & 25 & $16-37$ \\
\hline & $30-36 \mathrm{hr}$ & 1 & 1 & $0-7$ \\
\hline & $36>\mathrm{hr}$ & 1 & 1 & $0-7$ \\
\hline \multirow[t]{2}{*}{ Is the animal kept in a sheltered area? } & Yes & 41 & 47 & $36-58$ \\
\hline & No & 46 & 53 & $42-64$ \\
\hline \multirow[t]{2}{*}{ Is food and water provided before slaughter } & Yes & 51 & 65 & $53-75$ \\
\hline & No & 28 & 35 & $25-47$ \\
\hline
\end{tabular}

Animal welfare conditions during slaughter.

None $(100 \%)$ of the respondents interviewed indicated that stunning was performed before slaughter. In all cases but one, the goats were killed by exsanguination after slitting the throat with a 
knife. One person indicated that the head of the animal was put in a bucket of water while holding the feet to drown it. The most common (70\%) position of the goat before slaughter was on its side followed by $24 \%$ of respondents who indicated that the goat was held so that it lay on its back. Three (6\%) respondents indicated that the goat was hoisted by its hind legs from a tree or pole, before cutting the throat. Goats were mainly restrained during slaughter by assistants holding the heads and legs $(55 \%)$; while $33 \%$ said that the legs were tied together during slaughter; and $11 \%$ indicated that the head was tied to a tree and the legs held together (Table 3).

Table 3: STUNNING, RESTRAINT AND POSITION OF THE GOAT BEFORE SLAUGHTER.

\begin{tabular}{|c|c|c|c|c|}
\hline \multirow[b]{2}{*}{ Questions } & \multirow[b]{2}{*}{ Answers } & \multicolumn{3}{|c|}{ Respondents } \\
\hline & & $\mathbf{n}$ & $\%$ & CI: $95 \%$ \\
\hline \multirow[t]{2}{*}{ Is the animal stunned } & Yes & 0 & 0 & $0.0-3.45$ \\
\hline & No & 105 & 100 & $96.55-100$ \\
\hline \multirow[t]{4}{*}{$\begin{array}{l}\text { How is the animal restrained or handled } \\
\text { during slaughter }\end{array}$} & $\begin{array}{l}\text { Head and legs held by } \\
\text { assistants }\end{array}$ & 53 & 55 & $44-65$ \\
\hline & The legs tied together & 32 & 33 & $24-43$ \\
\hline & $\begin{array}{l}\text { The head is tied to a tree and } \\
\text { the legs are held }\end{array}$ & 11 & 11 & $6-19$ \\
\hline & $\begin{array}{l}\text { Hold the feet and drown the } \\
\text { goat in a bucket of water }\end{array}$ & 1 & 1 & $0-6$ \\
\hline \multirow[t]{3}{*}{ Position of the goats during slaughter } & Animal lying on its side & 35 & 70 & $55-82$ \\
\hline & Lying on its back & 12 & 24 & $13-38$ \\
\hline & Hung upside down & 3 & 6 & $1-17$ \\
\hline
\end{tabular}

The most common method of slitting the throat was sawing back and forth with the knife $(98 \%)$. Only $2 \%$ described a swift single cut method. The majority of respondents $(68 \%)$ stated that death occurred within 10 minutes of cutting the throat; while $32 \%$ indicated that it took more than 10 minutes. Respondents were asked how they knew the goat was dead. Signs of death that were described were: just looking at the goat one could see it was dead; when breathing stopped; when the eyes were no longer moving; when it stopped kicking; when it was no longer making a noise; if it urinated after the throat was slit; when there was no movement and the tongue hangs out; and, when blood stops pumping out. 


\section{Results from the four traditional slaughter ceremonies}

The results of the four traditional slaughter ceremonies were in agreement with those indicated by the respondents during the interviews. In all the four ceremonies; the mode of transport used was a car, the cars had no protective cover, the method of restraint was the same during transport and before slaughter, goats were kept for $<8$ hours, no feed or water was provided during transport and before slaughter and no stunning was performed before exsanguination (Table 4).

Table 4: THE FOUR TRADITIONAL SLAUGHTER CEREMONIES OBSERVED DURING THE STUDY.

\begin{tabular}{|c|c|c|c|c|}
\hline & \multicolumn{4}{|c|}{ Slaughter ceremonies } \\
\hline & A & $\mathrm{B}$ & $\mathrm{C}$ & $\mathrm{D}$ \\
\hline Method of transport used & Car & Car & Car & Car \\
\hline Does the vehicle have a protective cover & No & No & No & No \\
\hline Method of restraint used during transport. & Tied legs & Tied legs & Tied legs & Tied legs \\
\hline Distance travelled from source to slaughter & $<10 \mathrm{~km}$ & $<10 \mathrm{~km}$ & $<10 \mathrm{~km}$ & $20-30 \mathrm{~km}$ \\
\hline Are feed and water given during transport & No & No & No & No \\
\hline Where is the animal kept & TUT & TUT & TUT & Kraal \\
\hline For how long is it kept before slaughter & $<8 \mathrm{hr}$ & $<8 \mathrm{hr}$ & $<8 \mathrm{hr}$ & $<8 \mathrm{hr}$ \\
\hline Is the animal kept in a sheltered area & Yes & Yes & Yes & No \\
\hline Is food and water provided before slaughter & No & No & No & No \\
\hline Is the animal stunned & No & No & No & No \\
\hline How is the animal restrained or handled during slaughter & HLH & HLH & HLH & HLH \\
\hline Position of the goats during slaughter & ALS & ALS & ALS & ALS \\
\hline
\end{tabular}

TUT $=$ Tied under a tree

$\mathrm{HLH}=$ Head and legs held by assistants

ALS = Animal lying on its side

\section{Discussion}

The objective of the study was to assess animal welfare issues during traditional slaughter of goats among communities living in and around Pretoria. Respondents included a cross section of both men and women who acknowledged that they had been involved in traditional slaughter of goats. They originated from both rural and urban areas in and around Pretoria. It was interesting that so many women had witnessed or been involved in traditional slaughter of goats, as it was expected before the study, that mainly men would be involved.

The study found that private motorcars were the most commonly used method of transport of goats for traditional slaughter. Although designed for transporting humans, rather than livestock, 
private vehicles belonging to friends and family were usually available at minimal cost and the indigenous goats in the area usually weigh only about 25 to $40 \mathrm{~kg}$. Therefore, access and affordability seem to be the drivers for this mode of transport. It is important to note that other studies have linked the type of transport vehicles used to animal welfare issues (Appleby M.C., Cussen V.A., Garcés L., Lambert L.A., \& Turner J., 2008; Ferlazzo, 2003; Minka \& Ayo, 2007). The methods of restraint during transport and slaughter were also found to be a controversial area for animal welfare. Authors have associated multiple injuries with improper restraint during transport and slaughter (Minka \& Ayo, 2007). Therefore, in order to reduce stress and injury during transport and slaughter, training of vendors and traditional slaughter practitioners on humane methods of restraint of goats during transport should be undertaken. Transporting a goat tied with its legs tied together in the boot of a car or on the back of a small pickup is likely to result in stress, which is a welfare issue. Mitigating this is the small distance covered $(10-50 \mathrm{~km})$ which means that the duration of travel at $60 \mathrm{~km}$ per hour would be $<60$ minutes.

Studies have shown that transporting animals over a short period of time rather than a longer period improves welfare and reduce injury (Minka \& Ayo, 2007). Those who purchase goats for slaughter should be encouraged to obtain them as close as possible (perhaps $<10 \mathrm{~km}$ ) from the place where slaughter is to occur. Although the results indicate that protective cover is not provided during transportation, this is unlikely to be a major animal welfare issue if the transport time is short and the goats are humanely restrained.

It can be seen from Table 2 that goats are often kept in a pen in the shade of a tree and fed and watered. This should be encouraged as it is likely to improve the welfare of animals prior to slaughter. The FAO recommends that animals held for more than 8 hours must be provided with water to prevent animal welfare concerns (FAO, 2013). However, this study has shown that keeping goats for more than 8 hours before traditional slaughter is not a common practice (See Table 2). 
Nonetheless, practitioners who keep goats overnight must ensure that water and feed are provided for as this will ensure that the welfare of goats while waiting to slaughter is not compromised.

None of the goats slaughtered for traditional purposes were stunned. This is not unusual in other forms of religious slaughter such as Kosher and Halal, it is however controversial as preslaughter stunning is known to reduce undue stress and pain. Furthermore, stunning is known to improve handling of animals and reduces the excessive use of force during restraint (Gregory, 2005). However, approved stunning methods for goats are not readily available in low income rural areas. Electric stunners are expensive, require regular maintenance and a source of power. Humane killers based on the captive bolt method require a firearm licence in South Africa and are also prohibitively expensive. Welfare societies like the NSPCA have made licenced slaughter-men available to assist traditional slaughter of cattle in South Africa. There are also conflicts of ideologies between traditional and conventional slaughter. For example, the cultural norms in traditional slaughter require animals not to be stunned as vocalization is often an indicator that the sacrifice been accepted by the ancestors. On the contrary, excessive vocalization during the conventional slaughter has been used as an indicator of poor animal welfare (Grandin, 2001).

Similar to what was reported by Gregory (2005), most goats were slaughtered lying on their side, manually restrained or with their legs tied (Gregory, 2005). Some respondents reported that the animal was hoisted prior to slaughter. Of interest is that hoisting seems to be more common in traditional slaughter where three or less people are involved. This may due to the fact that hoisting the goat makes it is easier to bleed and flay the animals. Hoisting before bleeding has been previously reported in other traditional or religious slaughter practices; with suggestions that the incidence of struggling seems to be less prevalent compared to manual restraint (Velarde et al., 2014). Nonetheless, it is better to hoist the carcase after the throat has been cut as hoisting a live goat by its back legs compromises its welfare. 
The study found that exsanguination was not smooth or rapid. The authors suggest that a sharp knife be used in order to facilitate a swift way of bleeding the animals with minimum pain. The type of knife required is affordable and available locally and sharpening prior to slaughter is an easily taught skill. Evidence obtained suggests that the time from bleeding to unconsciousness is far longer than it should be. It is possible that the throat slitting does not sever the carotid artery and jugular veins on both sides and it is strongly suggested that training in the correct method of slaughter is given to communities by the state veterinary services. It is also apparent that those who slaughter goats do not have a good grasp of the signs of death. This might also have influenced the perception of time from bleeding to unconsciousness. Gradin has developed a method of assessing unconsciousness in cattle, pigs, and sheep, which may be used for traditional slaughter (Grandin, 2015). It is evident from this study that the majority of traditional slaughter practitioners do not know how to assess unconsciousness in goats, an important indicator for possible animal welfare problems during slaughter. Therefore, authors are of the view that in designing an educational program for traditional slaughter practitioners emphasis should also made in this area of loss of unconsciousness.

\section{Conclusions}

The current method of transportation, restraint and exsanguination of goats during traditional slaughter has a negative impact on their welfare. Alternative methods to alleviate suffering during traditional slaughter of goats should be researched. Information on correct methods of transport and restraint would not involve extra cost to the community and it is essential that information is provided on the correct use of restraint and sharp knives during exsanguination, to decrease suffering.

None of the above recommendations would compromise the religious norms associated with traditional African slaughter of goats. This information should form part of a specific veterinary extension campaign, possibly funded by non-governmental organisations involved in promoting animal welfare. Veterinarians and para-veterinarians should also be trained in humane methods of 
traditional slaughter at undergraduate level, so that they can demonstrate the correct methods to small-scale farmers and community members in their areas. It is recommended that culturally appropriate videos on humane transport, restraint and slaughter of goats be produced for use in South Africa. It is well known that slaughter methods that compromise livestock welfare also compromise food safety and human health, so it is urgent that this matter be properly addressed.

\section{Acknowledgment}

This study was conducted under the Safe Food Fair Food project of the International Livestock Research Institute (ILRI), funded by International Agricultural Research, GTZ, Germany (Project no:07.7860.5-001.00). Funding from the National Research Foundation is also gratefully acknowledged. This study was approved by the Ethics Committee of the Faculty of Veterinary Science at the University of Pretoria.

\section{References}

Appleby M.C., Cussen V.A., Garcés L., Lambert L.A., \& Turner J. (2008). Long distance transport and welfare of farm animals. Long distance transport and welfare of farm animals (pp. 1-450)

Behrens, K. (2009). Tony yengeni's ritual slaughter: Animal anti-cruelty vs. culture. South African Journal of Philosophy, 28(3), 271-289.

Brown, A. (2014). Denmark's ritual slaughter ban says more about human hypocrisy than animal welfare. Retrieved from

http://www.theguardian.com/commentisfree/andrewbrown/2014/feb/20/denmark-halal-kosha$\underline{\text { slaughter-hypocrisy-animal-welfare }}$ 
Council of the European Union. (2009). Council regulation (EC) no 1099/2009 of 24 september 2009 on the protection of animals at the time of killing (text with EEA relevance). Retrieved from http://eur-lex.europa.eu/legal-content/EN/ALL/?uri=CELEX\%3A32009R1099

FAO. (2013). CHAPTER 7: Slaughter of livestock. Retrieved from http://www.fao.org/docrep/003/x6909e/x6909e09.htm

Ferlazzo, A. (2003). Large animals transportation procedures in europe: Present and future. Veterinary Research Communications, 27, 513-514. doi:10.1023/B:VERC.0000014209.41666.ed

Grandin, T. (1991). Principles of abattoir design to improve animal welfare.

Grandin, T. (1998). Public veterinary medicine: Food safety and handling - objective scoring of animal handling and stunning practices at slaughter plants. Journal of the American Veterinary Medical Association, 212(1), 36-39.

Grandin, T. (2001). Cattle vocalizations are associated with handling and equipment problems at beef slaughter plants. Applied Animal Behaviour Science, 71(3), 191-201. doi:10.1016/S01681591(00)00179-9

Grandin, T. (2014). Animal welfare and society concerns finding the missing link. Meat Science, 98(3), 461-469. doi:10.1016/j.meatsci.2014.05.011

Grandin, T. (2015). How to determine insensibility (unconsciousness) in cattle, pigs, and sheep in slaughter plants. Retrieved from http://www.grandin.com/humane/insensibility.html

Gregory, N. G. (2005). Recent concerns about stunning and slaughter. Meat Science, 70(3), 481-491. doi:http://dx.doi.org/10.1016/j.meatsci.2004.06.026 
Gregory, N. G. (2008). Animal welfare at markets and during transport and slaughter. Meat Science, 80(1), 2-11. doi:DOI: 10.1016/j.meatsci.2008.05.019

Jacques, S. (2014). Science and animal welfare in france and european union: Rules, constraints, achievements. Meat Science, 98(3), 484-489. doi:10.1016/j.meatsci.2014.06.043

Masiga, W. N., \& Munyua, S. J. M. (2005). Global perspectives on animal welfare: Africa. Revue Scientifique Et Technique-Office International Des Epizooties, 24(2), 579-587.

Minka, N. S., \& Ayo, J. O. (2007). Effects of loading behaviour and road transport stress on traumatic injuries in cattle transported by road during the hot-dry season. Livestock Science, 107(1), 91-95. doi:10.1016/j.livsci.2006.10.013

Molomo, M., \& Mumba, T. (2014). Drivers for animal welfare policies in africa. Revue Scientifique Et Technique-Office International Des Epizooties, 33(1), 47-53.

Ohl, F., \& van der Staay, F. J. (2012). Animal welfare: At the interface between science and society. The Veterinary Journal, 192(1), 13-19. doi:http://dx.doi.org/10.1016/j.tvj1.2011.05.019

Qekwana, D., McCrindle, C., Oguttu,J. (2014). Designing a risk communication strategy for health hazards posed by traditional slaughter of goats in tshwane, south africa. Journal of the South African Veterinary Association, 85(1)

Qekwana, N. D., \& Oguttu, J. W. (2014). Assessment of food safety risks associated with preslaughter activities during the traditional slaughter of goats in gauteng, south africa. Journal of Food Protection, 77(6), 1031-1037. doi:10.4315/0362-028X.JFP-13-324

Ryan, G. W., \& Bernard, H. R. (2003). Techniques to identify themes. Field Methods, 15(1), 85-109. doi:10.1177/1525822X02239569 
Salamano, G., Cuccurese, A., Poeta, A., Santella, E., Sechi, P., Cambiotti, V., \& Cenci-Goga, B. T. (2013). Acceptability of electrical stunning and post-cut stunning among muslim communities: A possible dialogue. Society \& Animals, 21(5), 443-458. doi:10.1163/15685306-12341310

Shaddow, T. H. (1991). Religious ritual exemptions: Sacrificing animal rights for ideology. Retrieved from http://digitalcommons.lmu.edu/llr/vol24/iss4/14

Sneddon, L. U., Elwood, R. W., Adamo, S. A., \& Leach, M. C. (2014). Defining and assessing animal pain. Animal Behaviour, 97, 201-212. doi:10.1016/j.anbehav.2014.09.007

Tuyttens, F. A. M., Vanhonacker, F., Van Poucke, E., \& Verbeke, W. (2010). Quantitative verification of the correspondence between the welfare quality $(\mathrm{R})$ operational definition of farm animal welfare and the opinion of flemish farmers, citizens and vegetarians. Livestock Science, 131(1), 108-114. doi:10.1016/j.livsci.2010.03.008

Vanhonacker, F., Verbeke, W., Van Poucke, E., \& Tuyttens, F. A. M. (2008). Do citizens and farmers interpret the concept of farm animal welfare differently? Livestock Science, 116(1-3), 126-136. doi:10.1016/j.livsci.2007.09.017

Velarde, A., Rodriguez, P., Dalmau, A., Fuentes, C., Llonch, P., von Holleben, K. V., . . CenciGoga, B. T. (2014). Religious slaughter: Evaluation of current practices in selected countries. Meat Science, 96(1), 278-287. doi:10.1016/j.meatsci.2013.07.013

Velarde, A., \& Dalmau, A. (2012). Animal welfare assessment at slaughter in europe: Moving from inputs to outputs. Meat Science, 92(3), 244-251. doi:http://dx.doi.org/10.1016/j.meatsci.2012.04.009

Wyatt, C. (2015). Should religious slaughter be banned in the UK? - BBC news. Retrieved from http://www.bbc.com/news/uk-31411219 